Soltis, D. E., P. S. Soltis, M. D. Bennett and I. J. Leitch (2003): Evolution of genome size in Angiosperm. American J. Botany 90: 1596-1603.

Strasburger, E., F. Noll, H. Schenk and A. F. W. SchimPER (1991): Lehrbuch der Botanik für Hochschulen, 33. Auflage. Stuggart: Gustav Fischer.

Viruel, M. A., P. Escribano, M. Ferri and J. I. Hormaza (2005): Fingerprinting, embryo type and geographic differentiation in mango (Mangifera indica L., Anacardiaceae) with microsatellites. Molecular Breeding 15: 383-393.
XIE, L., Z. YANG, J. WEN, D. Li and T. YI (2014): Biogeography history of Pistacia (Anacardiaceae), emphasizing the evolution of the Madrean - Tethyan and the eastern Asian-Tethyan disjunctions. Molecular Phylogenetics and Evolution, 77: 136-146.

Zonneveld, B. J. M., I. J. Leitch and M. D. BennetT (2005): First nuclear DNA amounts in more than 300 angiosperms. Annals of Botany, 6 (2): 229-244.

\title{
Phylogeography and genetic variability of the Arnica montana chemotypes in NW Iberian Peninsula
}

\author{
By M. Vera ${ }^{\left.1,2),{ }^{*}\right)}$, R. Romero ${ }^{3)}$, M. A. Rodríguez-Guitián( ${ }^{3)}$, R. M. Barros ${ }^{3)}$, C. Real ${ }^{4)}$ and C. BouzA ${ }^{1)}$
}

(Received $22^{\text {th }}$ January 2015)

\begin{abstract}
The threatened European species Arnica montana L. is a plant much appreciated in the pharmaceutical industry, Galicia (North-Western Spain) being one of the main supply regions. Two chemotypes based on the content of sesquiterpene lactones have been found in this area: a chemotype dominated by helenalins, common in Central Europe, and another dominated by dihydrohelenalins, only found currently in Galicia. The aim of this work was to analyse the phylogenetic relationships and genetic diversity of Arnica montana in Galicia and their concordance with previous biochemical and environmental information. Two polymorphic chloroplast markers were sequenced in individuals from populations showing significant biochemical differences and situated in different environments (heathland, hay-meadow and peatland). Three haplotypes, different from those previously described in Europe, were found in Galicia and our results suggest that one of them could be ancestral inside the species. Significant population differentiation was detected in the studied area but genetic diversity within populations was low, only showing variability in
\end{abstract}

\footnotetext{
1) Department of Genetics. Faculty of Veterinary. University of Santiago de Compostela. Campus of Lugo, ES-27002 Lugo, Spain.

2) Laboratory of Genetics Ichthyology, Department of Biology, Faculty of Sciences, University of Girona. Campus of Montilivi, ES-17071 Girona, Spain.

3) Department of Crop Production, Polytechnic School, University of Santiago de Compostela. Campus of Lugo, ES-27002 Lugo, Spain.

4) Department of Ecology and Cellular Biology, Polytechnic School, University of Santiago de Compostela. Campus of Lugo, ES-27002 Lugo, Spain.

*) Corresponding author: MANUEl Vera. TLF +34 9828224 28, Fax +34 9828224 28. E-Mail: manuel.vera@usc.es, manuel. verar@udg.edu
}

heathland populations. This study is the first one describing the genetic diversity of Arnica montana in the extreme SW of Europe. The results suggested the presence of two different genetic groups (one of them ancestral) and were congruent with the two chemotypes described. Plants from heathlands displayed the highest variability because the two chemotypes were present in them. Future design of conservation and economical management plans for this threatened species should take into account this genetic variability and prioritize further genetic and chemical characterizations across the distribution range of the species.

Key words: Arnica montana, genetic variability, chloroplast DNA, sesquiterpene lactones, phylogeography, conservation.

\section{Introduction}

European arnica (Arnica montana L., Asteraceae) is a plant with traditional medicinal use. In spite of its current classification as "Least Concern" by the European Red List of vascular plants, the monitoring of population is recommended due its strong regional decline (IUCN, 2014). Major threats are pharmaceutical industry exploitation, habitat loss partly due to agriculture, abandonment of land, and reforestation (LUIJTEN et al., 2000; IUCN, 2014). As a consequence, several European countries have included $A$. montana in national red lists or approved laws for protection of its wild resources. The Galician region (NW Spain) is one of the main suppliers of A. montana for the European pharmaceutical industries but, unfortunately, no legislation on its exploitation is currently applied. In recent decades a significant decline in the populations of arnica in Galicia has been documented (LANGE, 1998; ROMERO et al., 2011).

Due to the morphological variability of $A$. montana, some subspecies and varieties have been described with- 
in its distribution area (TUTIN et al., 1980). Bolos y VAYREDA (1945) described the subspecies A. montana ssp. atlantica from individuals collected in the Southwest of France, North of Spain, and Portugal. Its presence has never been reported outside of this area. This author considered that smaller size, thinner floral stems, lanceolate leaves, and smaller flower heads with less bracts were the morphological characters differentiating this subspecies from A. montana ssp. montana. In addition, their habitat preferences would also be distinct, with $A$. $m$. atlantica growing between 0-400 m (maximum $1000 \mathrm{~m}$ ) in areas of oceanic climate and $A . \mathrm{m}$. montana growing between $1000-2800 \mathrm{~m}$ in areas under a more continental climate. The distribution map included in Bolos y VAYREDA (1945) suggests that $A . m$. atlantica would be widespread in Galicia whereas $A$. $m$. montana would be present only in mountain ranges near the eastern limit of the region.

However, a recent report of biometrical data from 310 individuals of $A$. montana collected in 37 populations in Galicia (Romero et al., 2011) questioned the validity of the subspecies proposed by BoLOs y VAYREDA (1945). None of the individuals fulfilled all the required characteristics of each subspecies and most characteristics varied continuously without clearly defining two groups of individuals. These results were in agreement with the morphological variability of $A$. montana observed by other authors in some areas of NW Iberia next to the Galician border (Asturias region: LAínZ, 1982; CastileLeón region: Nieto Feliner, 1985; GonzÁlez DE PAZ 2012). Nevertheless, ROMERo et al. (2011) reported that A. montana plants in Galicia are smaller when growing in grazed or mowed meadows and peatlands, and larger when growing in mountain $(>1200 \mathrm{~m})$ heathlands. The data also showed that the altitude factor was not the cause of these differences and the authors proposed that they might be due to grazing or mowing pressures associated with the different habitats.

Nowadays $A$. montana is a plant with a high demand for the pharmaceutical industry, which is interested in the secondary metabolite extracts from the flowering heads. Sesquiterpene lactones (SL) are the main compounds responsible for the anti-inflammatory properties of A. montana extracts (WILLUHN, 2004). Helenalin esters $(\mathrm{H})$ showed more active anti-inflammatory properties than dihydrohelenalin esters (DH) (KLAAS et al., 2002) while DH are less allergenic than H (LASs et al., 2008). Studies on the SL in extracts of flowers collected in different arnica populations of Galicia have revealed the existence of two different chemotypes in this area (PERRY et al., 2009). The first one is characterized by the predominance of $\mathrm{H}$, similar to the chemotype common in

Table 1. - Environmental, phytochemical and molecular information for each individual plant analysed in the study. Helenalin (H) and dihidrohelenalin (DH) contents and cpDNA haplotypes for each individual and haplotype diversity (h) and nucleotide diversity $(\pi)$ for each sampling site are included.

\begin{tabular}{|c|c|c|c|c|c|c|c|c|}
\hline Sampling site & Individuil & $\begin{array}{l}\text { LEGO Herkari un] } \\
\text { Voucher code }\end{array}$ & $\begin{array}{c}\mathrm{H} \\
\text { (mogg plant dry wielghel }\end{array}$ & 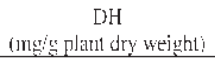 & Chemolype & rps] in intren] & ycti cemA spacer & combilled \\
\hline Ponte Pudidido & PPLD」 & 1406 & 1.70 & $8.30^{\circ}$ & Iberisin & Hapl & [lup] & Hap1 \\
\hline $505 \mathrm{~m}$ & РPED2 & 1407 & 1.22 & $15.73^{\circ}$ & Iberian & Hapl & Ilapl & Hap1 \\
\hline featlausd & P't'bly3 & 1408 & $0.899^{\prime}$ & $10.12^{-}$ & Ibertictr & Hapl & Ilapl & Hapl \\
\hline PPELD & PPLD4 & 1409 & $0.87^{*}$ & $13.70^{\circ}$ & Iberián & Hapl & Ilapl & Hap] \\
\hline 0." $55000^{\prime \prime}$ & PPED5 & 1410 & $0.68^{\prime \prime}$ & 10.26 & Iberian & Hapl & Ilup! & Hap1 \\
\hline \multirow{5}{*}{$43^{\circ} 17^{\prime} 10^{\circ} \mathrm{A}$} & Pe'tiso & 1411 & $0.27 \cdot$ & $6.18:$ & Ibetialn & Hapl & Hipl & Map1 \\
\hline & PPI:[D? & 1412 & $0.46^{\prime \prime}$ & 6.96 & Iberians & Hanel & |laip| & Hap] \\
\hline & PPEDS & 1413 & $0.7 \xi^{\prime}$ & 10.27 & Iberian & Hapl & Ilapl & ऊар1 \\
\hline & PEELID9 & 1414 & $1.00^{\prime \prime}$ & $11.80^{\circ}$ & Ibetictn & Haps & $\mathrm{MA}$ & $\mathrm{VA}$ \\
\hline & $r$ & & & & & 0,000000 & 0.000000 & 0.000000 \\
\hline Reilucha & RLIII\}] & 1416 & $0.42^{\prime \prime}$ & $10.088^{2}$ & Iberian & Hapl & Hepl & Hapl \\
\hline $179 \mathrm{~m}$ & RHIIH2 & $1: 117$ & 1.1)6 & $12.7 \mathrm{~S}$ & Iherian & Haipl & Hapl & Hap] \\
\hline Hay meatew & RI:II\}? & 1418 & $0.59^{\prime}$ & $9.28^{2}$ & Iberials & Hapl & |lip| & [tap] \\
\hline KLIB & RLIIIS4 & 1419 & $0.76^{\prime \prime}$ & $8.70^{\circ}$ & Iberian & Hapl & Hapl & Hapl \\
\hline (6)" $18^{\circ} 35^{\prime \prime} \mathrm{W}$ & RFIBST & $1: 120$ & $0.90^{\prime}$ & $9.61^{*}$ & Iberian & Hapl & Hapl & Hap] \\
\hline \multirow[t]{6}{*}{$42: 16^{\circ} 55^{\circ} \times$} & RIIII\}G & 1421 & $1.58:$ & $12.60^{\circ}$ & Iherian & Hapl & |lip| & [Hap] \\
\hline & RLIII37 & 1422 & 1.27. & $9.50^{\circ}$ & Iterian & Hapl & $\mathrm{H}$ Lipl & Hapl \\
\hline & RHIHS & $112:$ & $0.54:$ & 6.34 & Iherima & Hapl & Halpl & Häp] \\
\hline & RI!IIY! & 1424 & $1.19^{\prime \prime}$ & $7.83^{4}$ & Iberian & Hapl & $\mathrm{BA}$ & $V_{A}$ \\
\hline & $\mathrm{h}$ & & & & & 0.06060 & $(3.09100)$ & 0.00001 \\
\hline & $\pi$ & & & & & noonoon) & co.0000000 & 0.0000000 \\
\hline Ato do Couto & $\operatorname{col}[1$ & 1.376 & $3.92^{4}$ & $2.46=$ & Central-Fintopent & Hap? & H:р2 & Hap2 2 \\
\hline $1.330 \mathrm{~m}$ & $\mathrm{COl}: 2$ & 1.377 & $10.84^{1}$ & $3.966^{\circ}$ & Gontral-Furghean & H:Llp 2 & Help2 2 & Hap? \\
\hline Ilemilhlaticl & $\operatorname{col}^{\circ} 3$ & 1378 & 6. $16^{\prime \prime}$ & $369^{2}$ & 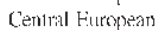 & Hap? & Ilap2 2 & Hap2 \\
\hline cot & $\cot [4$ & 1379 & $10.23^{1}$ & $1.6 ?^{*}$ & Cendlal-Finturean & Hapl & $\mathrm{H}$ :pl & Hapl \\
\hline $01^{\prime \prime} 05^{\prime} 37^{\prime \prime} \mathrm{k}$ & col:s & 1.380 & $33 x^{4}$ & $5.99^{\mathrm{i}}$ & IbetkisI & Hilp2 & $\mathrm{Help2}$ & Hap? \\
\hline \multirow[t]{5}{*}{$42=36=54\urcorner \mathrm{N}$} & $\operatorname{col}[6$ & 1.381 & $8.6 !^{\lrcorner}$ & $2017=$ & Central Fiturpesan & Hap? & II:ap2 & Hap2 \\
\hline & cot:s & 1.383 & $\left.4.5\right|^{4}$ & $5.19^{2}$ & Itbetลaร & Harp2 & Hinp2 & Hap2 2 \\
\hline & $\cot \mathrm{T} \perp 0$ & 1385 & $12.2 \mathrm{G}^{1}$ & $268^{:}$ & Contral-Eurguteal] & Hilp2 & Нup2 & Hap? \\
\hline & ln & & & & & 0.2500 & $\left.0.2 .500^{0}\right)$ & 0.25000 \\
\hline & $\pi$ & & & & & 0,000369 & 0,000408 & 0,000446 \\
\hline 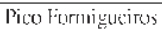 & PlOR 1 & 1628 & 7.77 & 305 & 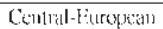 & H«ц2 & $H_{* เ \rho 2} 2$ & $\mathrm{H}$ : $\mu 2$ \\
\hline $1635 \mathrm{~m}$ & PFOR2 & 1629 & 10.25 & 3.64 & Cenntril-Euқрреыл & Hap 2 & II:L2 & Hap? \\
\hline Tleathlind & PlOR4 4 & 1631 & 8.72 & 2.34 & Centril biropean & Hap2 & IJip2 & Hap2 \\
\hline Pl:OR & PlOR5 & 1632 & 7.40 & 2.48 & Contril-Burguean & Help 2 & $\mathrm{H}_{\mathrm{a} i p 2}$ & Hap2 \\
\hline $01^{-1} 05^{\circ} 56^{\circ} \mathrm{x}$ & PFOR? & 16.94 & 7.78 & 1.84 & Cenlriul-Europeuis & Hapl & II:ı2 & Нарј \\
\hline \multirow[t]{3}{*}{$42=3622 \times$} & PIOR8 & 1635 & 7.17 & 2.12 & Central Fiturepeata & Hapl & IKap? & Hap3 \\
\hline & PFOR 10 & 1637 & 6.59 & 3.67 & 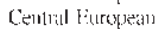 & $\mathrm{H}: 4 \hat{\mathrm{l}}$ & $V A$ & $V_{A}^{A}$ \\
\hline & li & & & & & 0.5711 & 0.0000 & $0.53,3$ \\
\hline
\end{tabular}

${ }^{a}$ Data from PERRY et al. (2009). NA: Not Analysed. 
Central Europe and only detected in arnica populations living in heathlands of the eastern mountains of Galicia. The second chemotype is characterized by a dominance of $\mathrm{DH}$ compounds. It was found in individuals growing in peatlands and hay-meadows of a large range of altitudes (from 420 to $1460 \mathrm{~m}$ ) and it was not described in the rest of Europe (PERRY et al., 2009). Hereinafter, they will be indicated as Central-European and Iberian chemotype, respectively.

Although the taxonomic status of the A. montana subspecies is doubtful in the study area (ROMERo et al., 2011), the morphological and chemotypical variability described above suggests the possible existence of genetic differences among arnica populations in this area. Genetic studies on this species are scarce (KAHMEN and Poschlod, 2000; LuiJTen et al., 2000; EKEnÄs et al., 2007, 2009) despite the economical and conservation interests of the species. Therefore the main objective of this study was to investigate for the first time the phylogeography and genetic variation associated with the two previously described chemotypes for A. montana in order to consider this information for the conservation strategy of the species in Galicia and provide more effective management plans.

\section{Materials and Methods}

\section{Sampling strategy}

The genetic analyses were performed on herbarium material collected from previous studies on ecology and chemistry of A. montana in Galicia (PERRY et al., 2009) and stored at the LUGO Herbarium, Universidade de Santiago de Compostela (Table 1). The selected material came from four locations showing the highest SL content differentiation in the region: the individuals from Reibocha (REIB) and Ponte Pedrido (PPED) corresponded to the Iberian chemotype (dihydrohelenalin dominated) and those from Pico Formigueiros (PFOR) corresponded to the Central-European chemotype (helenalin dominated). In the fourth location, Alto do Couto (COUT), most individuals showed the Central-European chemotype but two belonged to the Iberian chemotype (Table 1, Fig. 1). These locations also represent the different habitats of the species in this zone: high-altitude heathlands (COUT, PFOR), peatlands (PPED) and haymeadows (REIB). Collected plants in each location were selected well apart to ensure sampling of different individuals under vegetative reproduction (KAHMEN and Poschlod, 2000).

\section{Helenalin $(H)$ and dihydrohelenalin $(D H)$ content}

SLs data ( $\mathrm{H}$ and $\mathrm{DH}$ content) from individuals of REIB, PPED, and COUT sites were previously published (PERRY et al., 2009) whereas individuals of PFOR were analysed in this study at the first time. The methods for purification, identification, analytical extraction, and reversed-phase liquid chromatography (RPLC) analyses for SLs were done according to Douglas et al. (2004) and PERRY et al. (2009).

\section{DNA extraction, PCR amplification and sequencing}

Approximately $3 \mathrm{mg}$ of dried leaf were used to extract genomic DNA for each individual using the DNeasy Plant Mini Kit (Qiagen, Valencia, CA, USA).

Available resources on public DNA databases are very scarce. In order to select the most informative DNA

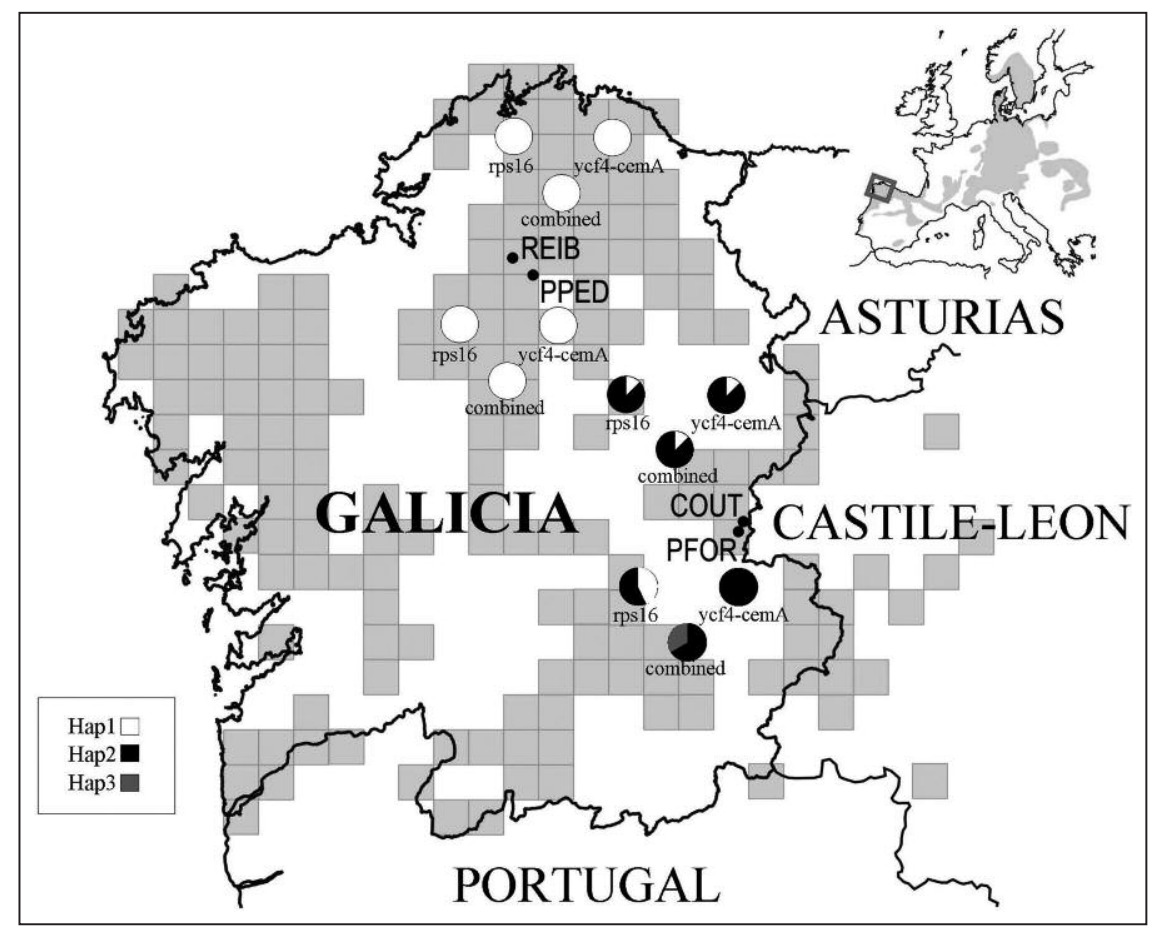

Figure 1. - Distribution of the studied locations. Sampling sites and haplotype distribution in the studied area for rps16 intron (rps16), ycf4-cemA spacer (ycf4-cemA) and both combined markers (combined). Shady areas show the distribution of $A$. montana in Europe (in grey) and in Galicia (grey squares). 
markers, available GenBank sequences for the species were downloaded. These sequences came from two voucher individuals, one of them from Sweden (MO-1 Sweden, Andreasen 304 (UPS)) and another from France (herb. France, s.c. 500084 (DS)). The alignments were performed using ClustalX 2.0 (THOMPSON et al., 1997) for five non-coding chloroplast DNA (cpDNA) regions (rpl16 intron (Swedish voucher specimen: AM690527, French voucher specimen: AM690540), rps16 intron (AM690611, AM690625), trnT-L spacer (AM690489, AM690504), psbA-trnH spacer (AM690567, AM690582), and ycf4-cemA spacer (AM690643, AM690654)) and two nuclear regions (ITS 18S-26S (AM690714, AM690729) and ETS (AM690673, AM690688)) previously analysed in the phylogeny of the genus Arnica (EKENÄS et al., 2007). The most variable DNA regions, rps16 intron and the $y c f 4$-cemA spacer, were selected for further amplification in this study, using the following primers: i) rpsf (5'-GTGGTAGAAAGCAACGTGCGACTT-3') and rps16r2 (5'-TCGGGATCGAACATCAATTGCAAC-3') for rps16 intron (OXELMAN et al., 1997), ii) rbcL/cemA-F5 (5'-CTCCGATTTCTTATAAAAGATATTCAG-3') and cemA-R (5'-AGTATTCCACCAAGTAGTAACCCAAG-3') for $y c f 4$-cemA spacer (provided by B. OxELMAN). PCR reaction mixture $(50 \mu \mathrm{L})$ contained 100-300 ng of template DNA, 1X PCR Gold Buffer, $2.0 \mathrm{mM} \mathrm{MgCl}, 100 \mu \mathrm{M}$ of each dNTP, $10 \mathrm{pmol}$ of each primer, and 2.5 units of AmpliTaq Gold ${ }^{\mathrm{TM}}$ DNA polymerase (Applied Biosystems, Foster City, CA, USA). PCR were carried out in a PTC- $100^{\mathrm{TM}}$ thermocycler (MJ Research) as follows: initial denaturation at $95^{\circ} \mathrm{C}$ for 10 min; 34 cycles of $95^{\circ} \mathrm{C}$ for $30 \mathrm{~s}$, annealing at $50^{\circ} \mathrm{C}$ for 1 min and $72{ }^{\circ} \mathrm{C}$ for $2 \mathrm{~min}$; and final extension at $72^{\circ} \mathrm{C}$ for $10 \mathrm{~min}$. PCR products were purified using the Spinclean PCR Purification Kit (MBiotech, Seoul, South Korea) and sequenced following the ABI Prism BigDye ${ }^{\mathrm{TM}}$ Terminator v3.1 Cycle Sequencing Kit protocol on an ABI 3730 sequencer (Applied Biosystems, Foster City, CA, USA).

\section{Analysis}

Sequence alignment was carried out using the program ClustalX 2.0. The retrieved GenBank sequences
AM690611 and AM690643 (belonging to the Swedish voucher specimen) were used as reference sequences to align the rps16 intron and $y c f 4$-cemA spacer markers, respectively. Variable sites for both markers were checked by hand using SEQSCAPE 2.5 (Applied Biosystems, Foster City, CA) and haplotypes were identified using Mega 5.05 (TAMURA et al., 2011).

To determine the phylogenetic relationships of the detected A. montana haplotypes, Median-Joining networks (BANDELT et al., 1999) using molecular markers individually and concatenated were constructed with NETWORK version 4.5.1.0 (http://www.fluxus-engineering.com/sharenet.htm). Available GenBank sequences from different Arnica taxa phylogenetically related with A. montana were included (EKENÄS et al., 2007, see Appendix 1 for species and accession numbers). Gaps (including one or more indels) among aligned sequences were considered as a single mutational step. The networks were rooted using the sequences of $A$. unalaschcensis as outgroup due its basal position in the Arnica genus (EKENÄs et al., 2007).

Genetic variability within locations was estimated by haplotype (h) and nucleotide $(\pi)$ diversity estimators (NEI and TAJIMA, 1981) using Arlequin 3.1 (ExCOFFIER et al., 2005). Population differentiation estimates taking into account the nucleotide diversity $\left(\Phi_{\mathrm{ST}}\right)$ were also calculated. The nucleotide substitution models applied for each marker were estimated using the "best DNA model" option implemented in Mega 5.05: Tamura 3parameter model (TAMURA, 1992) with gamma value of 0.09 or without gamma value for rps16 intron and ycf4cemA spacer, respectively. Analysis of the molecular variance (AMOVA) was performed to study the distribution of genetic variation within and among location groups based on the chemotypes ( $\mathrm{H}$ vs $\mathrm{DH}$ dominance). The significance of population differentiation was tested performing 1,000 permutations. These analyses were carried out using Arlequin 3.1.

\section{Results}

All individuals were amplified for rps16 intron and $y c f 4$-cemA spacer markers except three individuals

Table 2. - Variable sites for A. montana in the rps16 intron and ycf4-cemA spacer haplotypes detected in this study. Each column indicates one variable site.

\begin{tabular}{|c|c|c|c|c|c|c|c|c|c|c|c|c|c|c|}
\hline & \multicolumn{6}{|c|}{ rp. 16 intron variable sites } & & \multicolumn{6}{|c|}{ w/4-cemA spacer variable sites } & \multirow[t]{2}{*}{ Combined markers } \\
\hline Haplotypes & 52 & 56 & 74 & 95 & 222 & 651 & Haplotypes & 35 & 713 & 807 & 818 & 947 & 948 & \\
\hline AMg90611 & $\mathrm{T}$ & $\mathrm{G}$ & A & $T$ & - & A & AM690643 & c: & G & $\mathrm{G}$ & - & $T$ & $\mathrm{C}$ & A. montana Sweden \\
\hline AM 690625 & $\mathrm{C}$ & - & - & ' & $\mathrm{G}$ & $?$ & AM 690654 & A & A & 'I' & $\mathrm{T}$ & $\mathrm{G}$ & 'I & A. moniana France \\
\hline Hap 1 & $\mathrm{~T}$ & $\mathrm{G}$ & $\Lambda$ & $\mathrm{T}$ & - & - & Hapl 1 & $\Lambda$ & $\mathrm{G}_{\mathrm{r}}$ & $\mathrm{G}$ & - & $\mathrm{G}$ & $\mathrm{T}$ & Hapl \\
\hline Hap2 & $\mathrm{l}$ & $\mathrm{G}$ & A & $\mathrm{G}$ & - & - & Hap2 & A & G & $\mathrm{G}$ & - & $\Gamma$ & $C$ & Hap2 \\
\hline Hap 1 & $\mathrm{~T}$ & $\mathrm{G}$ & $\Lambda$ & $\mathrm{T}$ & - & - & Hap2 & $\Lambda$ & G & $\mathrm{G}$ & - & $\mathrm{T}$ & C & Hap3 \\
\hline
\end{tabular}

"?" indicates no position present in the sequence, and “-” indicates indel. 


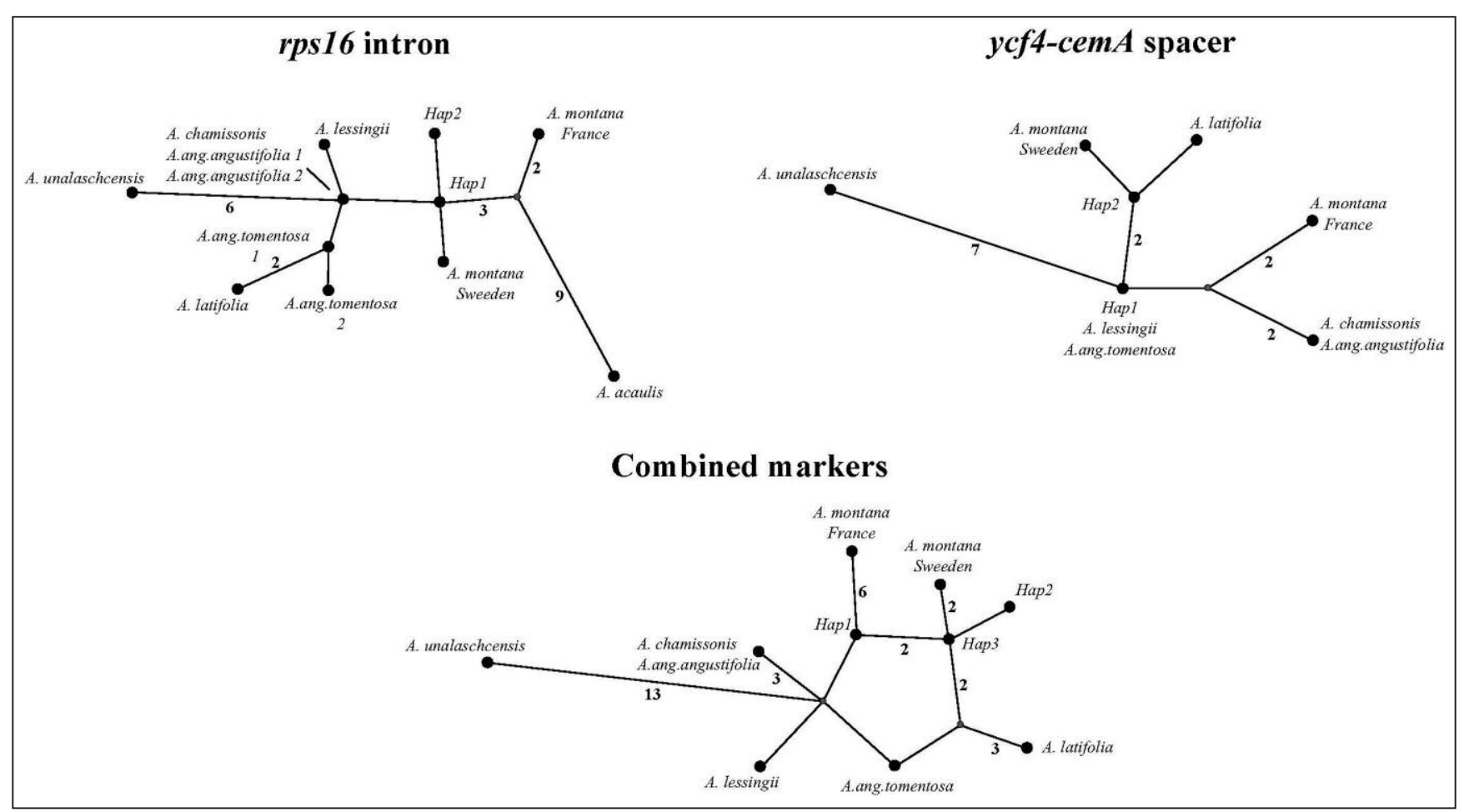

Figure 2. - Median-Joining networks of Arnica sp. haplotypes. Grey circles represent median vectors needed to connect all the observed haplotypes. Bold numbers indicate the mutational steps in lines where more than one mutational step is involved.

for $y c f 4$-cemA spacer (PPED9, REIB9 and PFOR10; Table 1).

The total length of aligned $A$. montana sequences was 680 base pairs (bp) for rps 16 intron and 1005 bp for ycf4cemA spacer. Two different haplotypes were detected for the two markers. The rps16 intron haplotypes only showed one variable site, whereas the $y c f 4$-cemA spacer haplotypes showed two variable sites in the zone under study (Table 2). Galician haplotypes for both markers were different from GenBank sequences from Sweden and France voucher specimens (Table 2). All novel haplotypes were submitted to GenBank (Accession numbers: KF679679 and KF679680 for rps16 intron; KF679681 and KF679682 for ycf4-cemA spacer).

There was congruence between haplotypes of the two cpDNA regions (Table 2). Thus, when an individual displays Hap1 in the rps16 region, Hap1 in ycf4-cemA spacer was found (combined Hap1). Just the same, individuals with Hap2 in the rps16 intron displayed Hap2 in the ycf4-cemA spacer (combined Hap2, Tables 1 and 2). There were only two exceptions (PFOR7 and PFOR8) where a third combined Hap3 was detected (rps16 intron Hap1 and ycf4-cemA spacer Hap2; Tables 1 and 2).

The maximum number of mutation events inside Arnica genus was 19 (between A. unalaschcensis and A. acaulis), 10 (A. unalaschcensis versus A. montana, A. latifolia, A. angustifolia ssp. angustifolia, A. chamisonis), and 20 (between A. unalaschcensis and A. montana) for rps16 intron (alignment length = $688 \mathrm{bp}$ ), $y c f 4$ cemA spacer (alignment length $=1026 \mathrm{bp}$ ) and combined markers (alignment length $=1711 \mathrm{bp}$ ), respectively (Fig. 2 ). Some species showed the same haplotype for the molecular markers. Thus, A. angustifolia ssp. angustifolia and $A$. chamisonis had identical haplotypes in both markers, while the ycf4-cemA spacer haplotypes for A. angustifolia ssp. tomentosa, A. lessingii and Hap1 were identical. Inside the species, the different networks grouped all the A. montana haplotypes. The most diverse sequences were always associated to the French voucher specimen. The phylogenetic relationships showed that the Hap 1 (either at individual or combined markers) was the most internal (Fig. 2). This internal position indicated the ancestrality of Hap1 inside A. montana.

The $\mathrm{H}$ content was higher than $\mathrm{DH}$ content for all PFOR individuals. Therefore, all of them were assigned to the Central-European chemotype (Table 1, Fig. 3). Genetic diversity was very low inside locations, with only H-dominated chemotype locations (heathlands) showing variability (Table 1 ). The $\Phi_{\mathrm{ST}}$ values were high and significant $(0.67731,0.89781$ and 0.84017 for rps 16 intron, $y c f 4$-cemA spacer and combined markers, respectively; $\mathrm{P}<0.001$ ), indicating genetic differentiation among sampling sites studied. AMOVA assigned the highest percentage of variability to differences among groups when sampling sites were grouped according to chemotype present in the population (rps16 intron: 72.84\%; ycf4-cemA spacer: 93.13\%; combined markers: $88.97 \%$, see Table 1 for chemotype assignment of the analysed populations) and very low fraction to differences among locations within groups $(<3.00 \%$ for all analyses performed). 


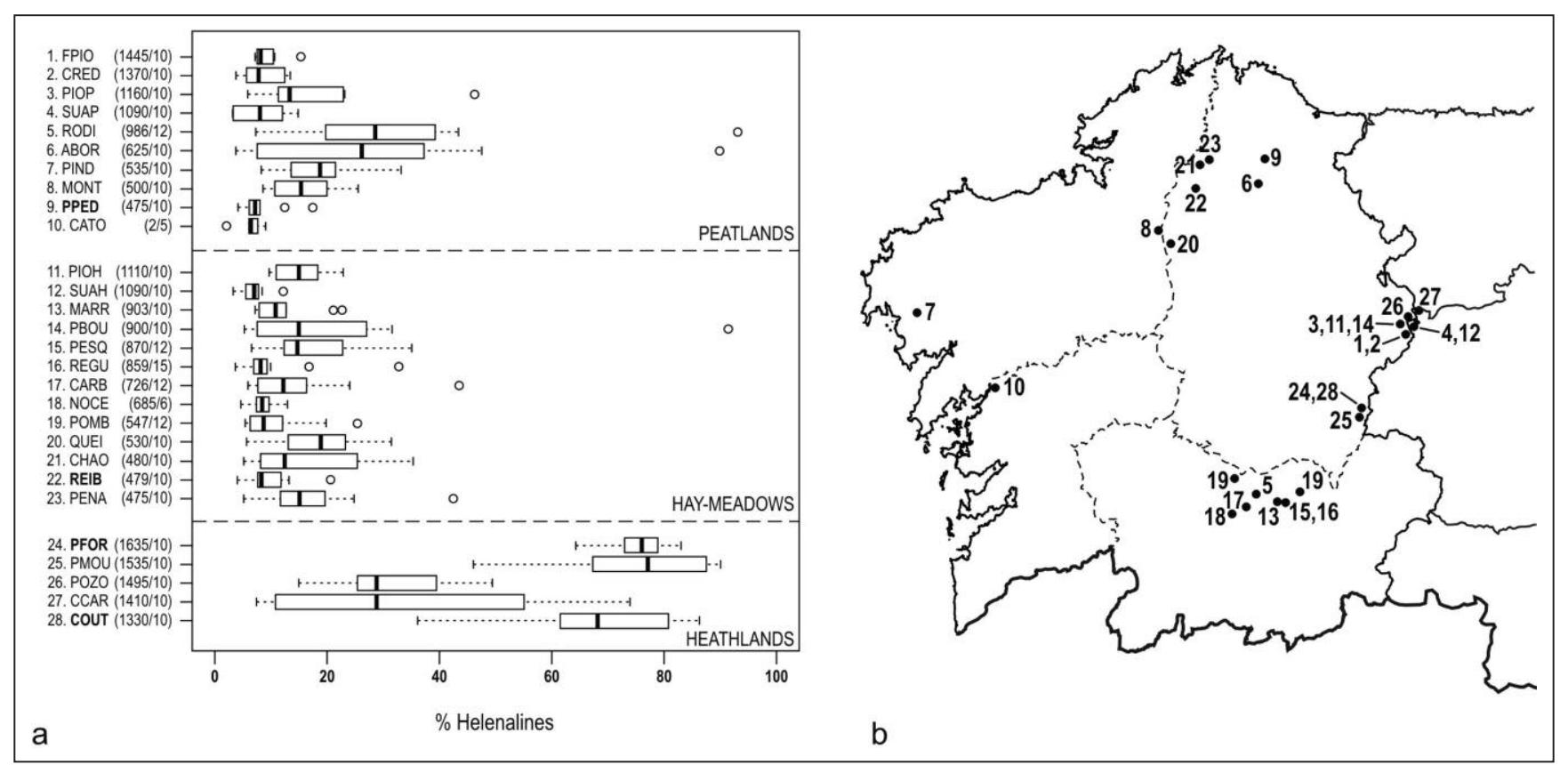

Figure 3. - (a) Boxplot of the percentage of helenalines in the populations studied in Galicia grouped by their habitat. The altitude and number of specimens analyzed of each population is indicated in parentheses beside their code name. The four populations selected for the genetic analysis have their code names in bold face. (b) Locations of the studied populations. Numeric codes as in (a).

\section{Discussion}

\section{Genetic variability}

This is the first study describing the genetic diversity of Arnica montana in the extreme SW of Europe. The number of mutational events among A. montana haplotypes were similar to the interspecific differences within the Arnica genus. Despite the low levels of variability detected in the DNA regions analysed, cpDNA haplotypes were congruent with chemotypes and geographical variation found in Galicia. Thus, although analysed data was limited, the presence of two different divergent chloroplast lineages cannot be ruled out. Significant population differentiation was detected in the studied zone, mostly assigned to differences among groups, suggesting the presence of two genetically divergent population groups. Moreover, one of these groups is different from the European A. montana reported to date, based on the phylogenetic and chemotypic data (EKENAS et al., 2007; PERRY et al., 2009), highlighting its conservation interest. Posterior studies on a broader area across the distribution range of the species, including more sampling sites, would help to corroborate the distribution of the suggested groups. Moreover, cpDNA inheritance (mainly maternal) can limit the definition of population ranges and evolutionary forces depicting the current distribution of genetic variability. Thus, the use of highly variable and codominant molecular markers (i.e. microsatellite loci, not available to date) will also allow us to refine these limits.

Phylogenetic networks grouped all the A. montana haplotypes and related them with $A$. angustifolia, the other European species (Fig. 2). Networks also showed that the Hap1 haplotypes (either individually or com- bined) were ancestral inside A. montana. These haplotypes were fixed in locations with Iberian chemotype. Thus, these Iberian locations may represent the source for post-glacial North-European colonisations (GoMEZ and LUND, 2006), being the Southernmost limit in Europe. Moreover, the presence of one haplotype combining Hap1 for rps16 intron and Hap2 for ycf4-cemA spacer (combined Hap3) was a surprising result. EkENÄS et al. (2007) suggested disrupted concerted evolution, hybridization processes and homoplasy to explain conflicting positions for different taxa using cpDNA and nuclear ribosomal markers. Presence of shared haplotypes suggests hybridization processes among species and complex phylogenetic relationships. Recurrent mutation produced in mutational "hotspots" leads to homoplasy among sequences. The genetic diversity was low, being the rps16 intron haplotypes only differed by one nucleotide site. Thus, recurrent mutation is the most plausible explanation for the combined Hap3 appearance, although cpDNA recombination cannot be ruled out (HUANG et al., 2001; MARSHALL et al., 2001).

\section{Environmental, chemical and molecular information}

Recent phylogenetic analyses showed congruence between molecular data and SL contents in the genus Arnica (EKENÄS et al., 2009). In addition, our study suggests the existence of relationships among cpDNA haplotypes, SL contents and habitat of the population. All individuals, except one, collected in hay meadow (REIB) or peatland (PPED) locations had combined Hap1 and all of them had Iberian chemotype. On the other hand, the individuals collected in heathland locations (COUT and PFOR) were more variable. Most of them (82\%) had 
Central-European chemotype and combined Hap2, but two individuals from COUT with Iberian chemotype had also combined Hap2, and two individuals from PFOR had Central-European chemotype and combined Hap3 (see Table 1). Moreover, one individual from COUT (COUT4), with Central-European chemotype, showed the combined haplotype Hap1, which was fixed in locations of Iberian chemotype. Thus, these incongruences suggest the presence of gene flow in the zone. Gene flow has been proposed for the maintenance of gene diversity and connectivity in fragmented A. montana populations (KAHMEN and PoschlOD, 2000). A possible explanation could be the transportation of seeds by wind or animals (including man).

These results cannot be extended to the whole Galician area because we selected populations with very different chemotypes in order to maximize the chance of finding genetic differences. The reduced number of sampling sites used in this study also limited the generalization/extrapolation of present results. For example, figure 3 shows the variability of the proportion of helenalines for the whole set of Galician populations studied so far (PERRY et al., 2009, unpublished data. Mean number of individuals analyzed per population $=10.1 \pm 1.7$, see Fig. 3) and information about altitude and habitat type. The chemotypes of REIB and PPED populations were clearly Iberian and showed small variability. The individuals from COUT and PFOR were more variable but the Central-European chemotype was the most abundant there. Other populations (e.g. RODI, ABOR, POZO, CCAR) showed high variability in SL composition and a mixture of both chemotypes, which suggests that these populations could also be genetically variable. Thus, further genetic analyses should be extended to other populations showing biochemical and/or habitats differences both in the studied region and in other European populations to generalize and support our observations (i.e. what the relationship between chemotype information and genetic information is).

On the conservation and sustainable exploitation of this species

Despite the fact that biometric data suggest that A. montana ssp. atlantica is not a good taxon, the results presented here showed that there is genetic and biochemical variability in the Galician populations that could be associated to habitat differences (including grazing pressure). Knowledge about the relationships between the genetic and chemical variability and the habitats where the species lives is a key point for the design of management plans that warrant the persistence of the species while allowing for its exploitation (ANDRosiuk et al., 2013). Not in vain the Annex V of the European Council Directive 92/43/EEC includes A. montana as a "plant species of community interest whose taking in the wild and exploitation may be subject to management measures". Maintenance of genetic diversity of socio-economically valuable species is one of the main targets of the Global Strategy for Plant Conservation 2011-2020 (CDB 2011-2020).

At present, there is no data about the distribution of the Iberian chemotype and the haplotypes found in this study outside Galicia. In case their distributions were restricted to this or nearby areas the risk of loss of genetic, pharmaceutical, and economic resources is high. Therefore, further genetic analyses must been performed to correlate biochemical and genetic information in order to define the proper conservation units (e.g. Iberian group vs Central-European group). Finally, management strategies should also prioritize habitat maintenance and exploitation regulation in order to allow the preservation of arnica diversity in the zone.

\section{Acknowledgments}

Authors wish to thank S. SÁNCHEZ-DARRIBA, M. LÓPEZ and S. GómEz for their technical assistance, Prof. B. OXELMAN for providing ycf4-cemA spacer primers, M.A. BYRNE and M. BYRNE to improve English. The authors are also grateful to Dr. B. DEgen, Dr. S. A. POHRT and Dr. R. H. KAO for their constructive comments on the earlier version of this manuscript. Purification, identification, analytical extraction and RPLC analyses for SLs in arnica plants were performed by Dr. Nigel PERRY's team of Plant \& Food Research (New Zealand). This research was supported by funding from GI-1251-ACUIGEN and GI-1648-SILVOPAST research groups of the University of Santiago de Compostela (Spain).

\section{References}

Androsiuk, P., A. Shimono, J. Westin, D. Lindgren, A. FRIES and X. R. WANG (2013): Genetic status of Norway spruce (Picea abies) breeding populations for northern Sweden. Silvae Genetica 62: 127-136.

BANDElt, H. J., P. Forster and A. Rohl (1999): Medianjoining networks for inferring intraspecific phylogenies. Molecular Biology and Evolution 16: 37-48.

Bolos y VayredA, A. (1945): El Arnica montana L. en la Península Ibérica. Farmacognosia. Anales del Instituto José Celestino Mutis 7: 145-151.

Douglas, J. A., B. M. Smallfield, E. J. Burgess, N. B. Perry, R. E. Anderson, M. H. Douglas and V. L. A. GLENNIE (2004): Sesquiterpene Lactones in Arnica montana: a rapid analytical method and the effects of flower maturity and simulated mechanical harvesting on quality and yield. Planta Medica 70: 166-170.

Ekenäs, C., B. G. BALdwin and K. AndREASEN (2007): A molecular phylogenetic study of Arnica (Asteraceae): Low chloroplast DNA variation and problematic subgeneric classification. Systematic Botany 32: 917-928.

EkenÄs, C., J. Rosen, S. Wagner, I. Merfort, A. BACKLUND and K. ANDREASEN (2009): Secondary chemistry and ribosomal DNA data congruencies in Arnica (Asteraceae). Cladistics 25: 78-92.

EXCoffier, L., G. LAVAL and S. SchneIder (2005): Arlequin (version 3.0): An integrated software package for population genetics data analysis. Evolutionary Bioinformatics 1: 47-50.

Gómez, A. and D. H. Lund (2006): Refugia within refugia: patterns of phylogeographic concordance in the Iberian Peninsula, pp. 155-188. In: Phylogeography in southern European refugia: Evolutionary perspectives on the origins and conservation European biodiversity, edited by S. Weiss \& N. FerRand, Academic Publishers, Dordrecht Kluwe. 
GonzÁlez DE PAZ, M. L. (2012): Flora y vegetación de La Cabrera Baja (León): valoración del estado de conservación. Ph. D. thesis, Universidad de León, Spain.

Huang, S., Y. C. Chiang, B. A. SchaAl, C. H. Chou and T. Y. CHIANG (2001): Organelle DNA phylogeography of Cycas taitungensis, a relict species in Taiwan. Molecular Ecology 10: 2669-2681.

IUCN (2014): Arnica montana. In IUCN 2014, The IUCN Red List of Threatened Species, Version 2014.2. Available from http://www.iucnredlist.org. Accessed on 25 Oct 2014.

Kahmen, S. and P. Poschlod (2000): Population size, plant performance, and genetic variation in the rare plant Arnica montana L. in the Rhön, Germany. Basic and Applied Ecology 1: 43-51.

KlaAs C. A., G. Wagner, S. Sosa, R. Della Loggia, U. Bomme, H. L. Pahl and I. Merfort (2002): Studies on the anti-inflammatory activity of phytopharmaceuticals prepared from Arnica flowers. Planta Medica 68: 385-391.

LAÍNZ, M. (1982): Mis contribuciones al conocimiento de la flora de Asturias. Discurso de recepción en IDEA el 12 de marzo de 1982; contestación de José $\mathrm{M}^{\mathrm{a}}$ Patac de las Traviesas, S. J. Diputación Provincial de Asturias, Instituto de Estudios Asturianos (C.S.I.C.), Oviedo, Spain.

LANGE, D. (1998): Europe's medicinal and aromatic plants: their use, trade and conservation. TRAFFIC International, Cambrigde.

Lass, C., M. Vocanson, S. Wagner, C. M. SchempP, J. F. Nicolas, I. Merfort and S. F. Martin (2008): Antiinflammatory and immune-regulatory mechanisms prevent contact hypersensitivity to Arnica montana L. Experimental Dermatology 17: 849-857.

LuiJten, S. H., A. Dierick, J. G. B. Oostermeijer, L. E. L. RaiJmann and H. C. M. Den NiJs (2000): Population size, genetic variation, and reproductive success in a rapidly declining, self-incompatible perennial (Arnica montana) in The Netherlands. Conservation Biology 14: 1776-1787.

Marshall, H. D., C. Newton and K. Ritland (2001): Sequence-repeat polymorphisms exhibit the signature of recombination in lodgepole pine chloroplast DNA. Molecular Biology and Evolution 18: 2136-2138.

NEI, M. and F. TAJIMA (1981): DNA polymorphism detectable by restriction endonucleases. Genetics 97: 145-163.

Nieto Feliner, G. (1985): Estudio crítico de la flora orófila del suroeste de León: Montes Aquilianos, Sierra del Teleno y Sierra de la Cabrera. Ruizia 2. Real Jardín Botánico, Consejo Superior de Investigaciones Científicas, Madrid, Spain.

Oxelman, B., M. Liden and D. Berglund (1997): Chloroplast rps16 intron phylogeny of the tribe Sileneae (Caryphyllaceae). Plant Systematics and Evolution 206: 393-410.
Perry, N. B., E. J. Burgess, M. A. Rodríguez-Guitián, R. Romero, E. Lopez, B. M. Smallfield, N. I. Joyce and R. P. LitTlejoHn (2009): Sesquiterpene lactones in Arnica montana: Helenalin and Dihydrohelenalin chemotypes in Spain. Planta Medica 75: 660-666.

Romero, R., C. Real, M. A. Rodríguez-Guitián, M. R. Barros, A. Rigueiro and M. P. GonzÁlez-HernándeZ (2011): Estudio de la variabilidad biométrica de Arnica montana L. (Asteraceae) en el extremo occidental cantábrico (NW Ibérico). In Actas del IX Col-loqui International de Botanica Pirenaico-Cantabrica.

TAMURA, K. (1992): Estimation of the number of nucleotide substitutions when there are strong transition-transversion and $\mathrm{G}+\mathrm{C}$-content biases. Molecular Biology and Evolution 9: 678-687.

Tamura, K., D. Peterson, N. Peterson, G. Stecher, M. NEI and S. KuMAR (2011): MEGA5: Molecular Evolutionary Genetics Analysis using maximum likelihood, evolutionary distance, and maximum parsimony methods. Molecular Biology and Evolution 28: 2731-2739.

Thompson, J. D., T. J. Gibson, F. Plewniak, F. JEAnMOUGin and D. G. Higgins (1997): The CLUSTAL_X windows interface: flexible strategies for multiple sequence alignment aided by quality analysis tools. Nucleic Acids Research 25: 4876-4882.

Tutin, T. G., V. H. Heywood, N. A. Burges, D. M. Moore, D. H. Valentine, S. M. Walters and D. A. WebB (1980): Flora Europaea. Cambrigde University Press, Cambrigde .

WilluHn, G. (2004): Arnicae flos. pp. 54-59. In Herbal drugs and phytopharmaceuticals, edited by M. Witchl, Scientific Publishers, Medpharm, Sttutgart.

\section{Appendix 1.}

Species and their GenBank accession numbers (among brackets) used in this study for the Arnica genus.

For rps16 intron: A. acaulis (AM690603), A. angustifolia ssp. angustifolia (AM690615, AM690629), A. angustifolia ssp. tomentosa (AM690630, AM690631), A. chamissonis (AM690616), A. latifolia (AM690618), A. lessingii (AM690619), A. montana (AM690611, AM690625), A. unalaschcensis (AM690614).

For ycf4-cemA spacer: A. angustifolia ssp. angustifolia (AM690647), A. angustifolia ssp. tomentosa (AM690656), A. chamissonis (AM690648), A. latifolia (AM690649), A. lessingii (AM690650), A. montana (AM690643, AM690654), A. unalaschcensis (AM690646).

Herausgeber: Johann Heinrich von Thünen-Institut. Bundesforschungsinstitut für Ländliche Räume, Wald und Fischerei. Schriftleitung: Institut für Forstgenetik, Sieker Landstrasse 2, D-22927 Grosshansdorf Verlag: J. D. Sauerländer's Verlag, Berliner Strasse 46, D-63619 Bad Orb Anzeigenverwaltung: J. D. Sauerländer's Verlag, Bad Orb

Gesamtherstellung: PPPP Norbert Wege e.K., Gladenbach — Printed in Germany. 